\title{
Boron-implanted 3C-SiC for intermediate band solar cells
}

\author{
Quanbao Ma ${ }^{1, a^{*}}$, Augustinas Galeckas ${ }^{1}$, Alexander Azarov ${ }^{1}$, \\ Annett Thøgersen ${ }^{2}$, Patricia Carvalho ${ }^{2}$, Daniel N. Wright ${ }^{3}$, Spyros Diplas ${ }^{2}$, \\ Ole M. Løvvik², Valdas Jokubavicius ${ }^{4}$, Xinyu Liư ${ }^{4}$, Jianwu Sun ${ }^{4}$, \\ Mikael Syväjärvi ${ }^{4}$, and Bengt G. Svensson ${ }^{1}$ \\ 1. University of Oslo, Department of Physics, Centre for Materials Science and Nanotechnology, \\ PO Box 1048 Blindern, N-0316 Oslo, Norway; \\ 2. SINTEF Materials and Chemistry, Forskningsveien 1, N-0373 Oslo, Norway \\ 3. SINTEF ICT, Forskningsveien 1, N-0373 Oslo, Norway \\ 4. Linköping University, Department of Physics, Chemistry and Biology, SE-58183 Linköping, \\ Sweden. \\ aquanbao.ma@smn.uio.no
}

Keywords: silicon carbide, 3C-SiC, cubic, boron, implantation, intermediate band, photovoltaic, solar cells

\begin{abstract}
Sublimation-grown 3C-SiC crystals were implanted with 2 atomic percent of boron ions at elevated temperature $\left(400{ }^{\circ} \mathrm{C}\right)$ using multiple energies $(100$ to $575 \mathrm{keV})$ with a total dose of $8.5 \times 10^{16}$ atoms $/ \mathrm{cm}^{2}$. The samples were then annealed at 1400,1500 and $1600{ }^{\circ} \mathrm{C}$ for $1 \mathrm{~h}$ at each temperature. The buried boron box-like concentration profile can reach $\sim 2 \times 10^{21} \mathrm{~cm}^{-3}$ in the plateau region. The optical activity of the incorporated boron atoms was deduced from the evolution in absorption and emission spectra, indicating possible pathway for achieving an intermediate band behavior in boron doped 3C-SiC at sufficiently high dopant concentrations.
\end{abstract}

\section{Introduction}

In recent years there has been increasing research efforts into the field of intermediate band solar cells (IBSCs) due to the potential for enhancing solar-to-electricity conversion efficiency [1]. The IBSC provides an opportunity for exceeding the Shockley-Queisser limit on efficiency for single junction cells by introducing an intermediate band (IB) in between the valence band edge (VB) and the conduction band edge (CB) of a semiconductor absorber layer. Theoretically, introducing an IB allows two photons with energy less than the bandgap to excite an electron from the VB to the CB. This increases the induced photocurrent and thereby the efficiency. Theoretical estimates have shown that efficiencies of $\sim 63 \%$ for IBSCs can be achieved under concentrated sunlight, which is a significant improvement relative to the corresponding maximum single junction efficiency of $40.7 \%$ [2].

The IBSC model faces challenges in finding a suitable semiconductor with an appropriately positioned IB in the bandgap. In fact, one attractive material for an IBSC is single crystalline cubic silicon carbide $(3 \mathrm{C}-\mathrm{SiC})$ offering a nearly ideal band gap $(2.3 \mathrm{eV})$ along with excellent electronic properties $[3,4]$. Boron (B) atoms substituting the silicon

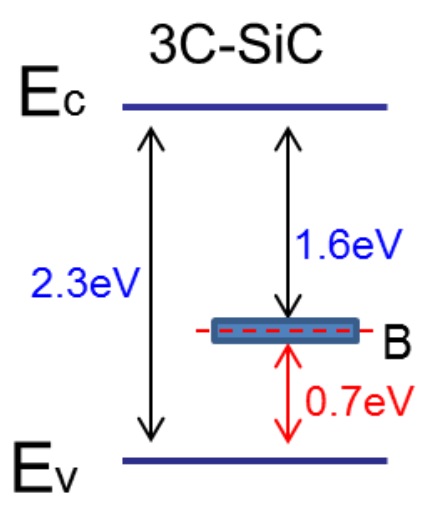
lattice sites in $\mathrm{SiC}$ form a relatively shallow accepter state at

Fig.1 Illustration of boron-related intermediate band in $3 \mathrm{C}-\mathrm{SiC}$.

$\sim 0.3 \mathrm{eV}[5]$. However, boron atoms can also form pairs with carbon vacancies $\left(\mathrm{B}_{\mathrm{Si}}-\mathrm{V}_{\mathrm{C}}\right)$, leading to the formation of the so-called deep boron level also labelled as "D center" [6]. Irrespective of the SiC polytype, the deep boron level occurs in the range of $\sim 0.5-0.7 \mathrm{eV}$ above the valence band edge, in 
accordance with the Langer-Heinrich rule [7-9]. Hence, the deep boron center is a suitable candidate to realize an IB in 3C-SiC, as schematically shown in Fig. 1. However, until recently no 3C-SiC material of sufficient quality has been available for studies of IBSCs, since typically $3 \mathrm{C}-\mathrm{SiC}$ forms with many domains. Recent advancement using sublimation epitaxy paves the way for single crystalline material of large domain size and sufficient thickness to provide free-standing substrates with appropriate charge carrier lifetimes [10].

In this work, single crystalline 3C-SiC samples have been implanted with 2 at. $\%$ of boron and then annealed at 1400,1500 and $1600{ }^{\circ} \mathrm{C}$ for $1 \mathrm{~h}$ at each temperature. The implanted samples were characterized by secondary ion mass spectrometry (SIMS), Rutherford backscattering spectrometry (RBS), photoluminescence (PL) spectroscopy and UV-vis spectrophotometry techniques. Tentative indication for the formation of a B-related IB is found.

\section{Experimental}

The sublimation-grown $3 \mathrm{C}$-SiC crystals were implanted with $\mathrm{B}$ ions at elevated temperature (400 ${ }^{\circ} \mathrm{C}$ ) using multiple energies (100 to $575 \mathrm{keV}$ ) with a total dose of $8.5 \times 10^{16}$ atoms $/ \mathrm{cm}^{2}$ to form a buried box-like concentration profile. The samples were then post-implant annealed at 1400, 1500 and 1600 ${ }^{\circ} \mathrm{C}$ for $1 \mathrm{~h}$ at each temperature. Prior to annealing, the samples were protected by a pyrolized resist film (carbon-cap) after native oxide etching, while the pyrolysis was performed in forming gas at 900 ${ }^{\circ} \mathrm{C}$ for $10-15 \mathrm{~min}$. The carbon was then removed after annealing by dry thermal oxidation.

The box-like concentration was measured by SIMS. The structural properties of the samples were analysed by RBS. Optical absorption properties were derived from the transmittance measurements performed at room temperature using a UV-VIS spectrophotometer. Photoluminescence (PL) measurements were carried out by employing $325 \mathrm{~nm}$ wavelength light from a cw HeCd laser as an excitation source. The emission was collected by a microscope and analyzed with a spectrometer system with a minimal resolution of $0.2 \mathrm{~nm}$. The PL measurements were performed at $10 \mathrm{~K}$ temperature using a closed-cycle He-refrigerator.

\section{Results and discussion}

The SIMS results are shown in Fig 2. The buried boron box-like concentration can reach $\sim 2 \times 10^{21}$ $\mathrm{cm}^{-3}$ in the plateau region, corresponding to $\sim 2$ atomic percent. The concentration profile almost does not change even after the 1400,1500 and $1600^{\circ} \mathrm{C}$ annealing.

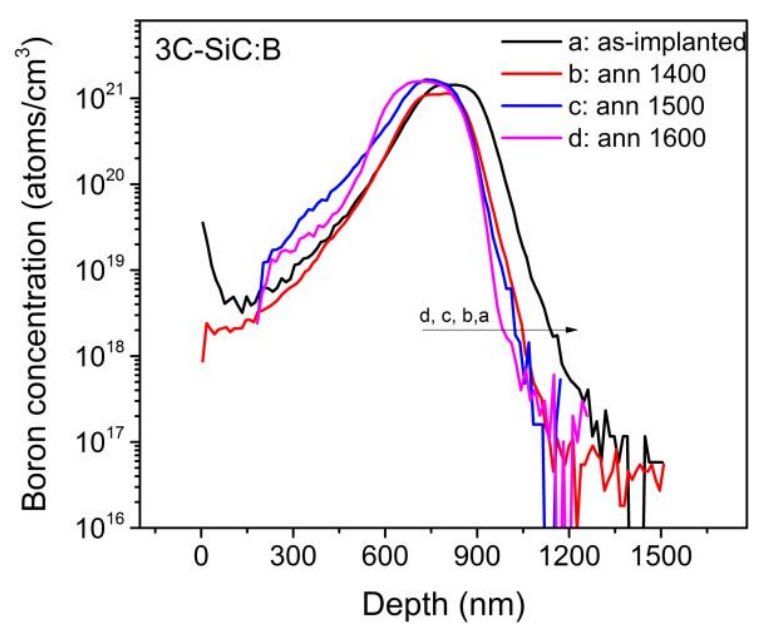

Fig.2. SIMS depth profiles of boron concentration in B-implanted 3C-SiC to 2 at. \%.

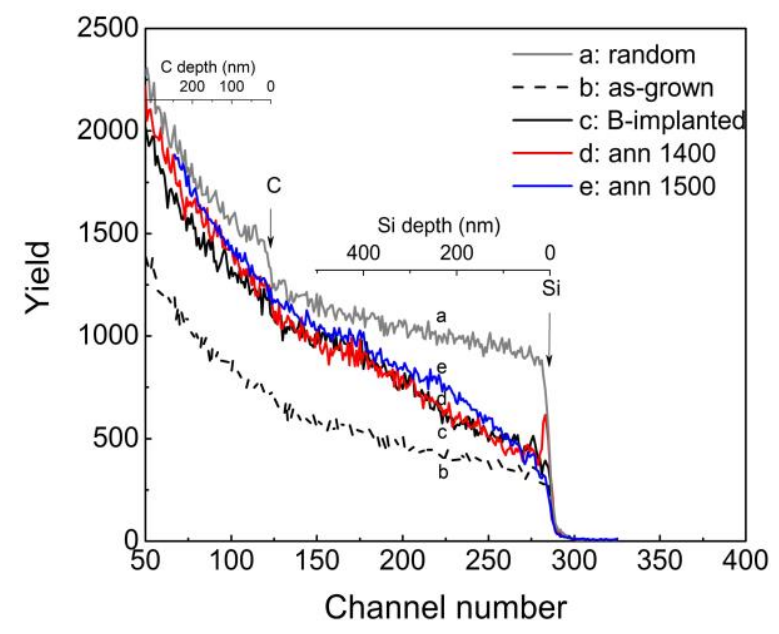

Fig.3. RBS channelled and random spectra of as-grown and B-implanted 3C-SiC prior and after annealing. 
In order to check the effect of implantation and annealing on the crystal quality, the RBS measurements were performed using a $\mathrm{He}$ ion beam of $1.6 \mathrm{MeV}$. The spectra were taken with the detector placed to a scattering angle of $165^{\circ}$. Fig. 3 shows the RBS channeled and random spectra of the sample in the as-grown state, B-implanted before and after annealing at 1400 and 1500 . The channel numbers of $\mathrm{Si}$ and $\mathrm{C}$ at the film surface are indicated in the figure by arrows. Fig. 3 indicates that the B implantation leads to damage accumulation on both the Si and C sublattices and causes the crystal quality to decrease. The damage level in the Si sublattice approaches the random level at
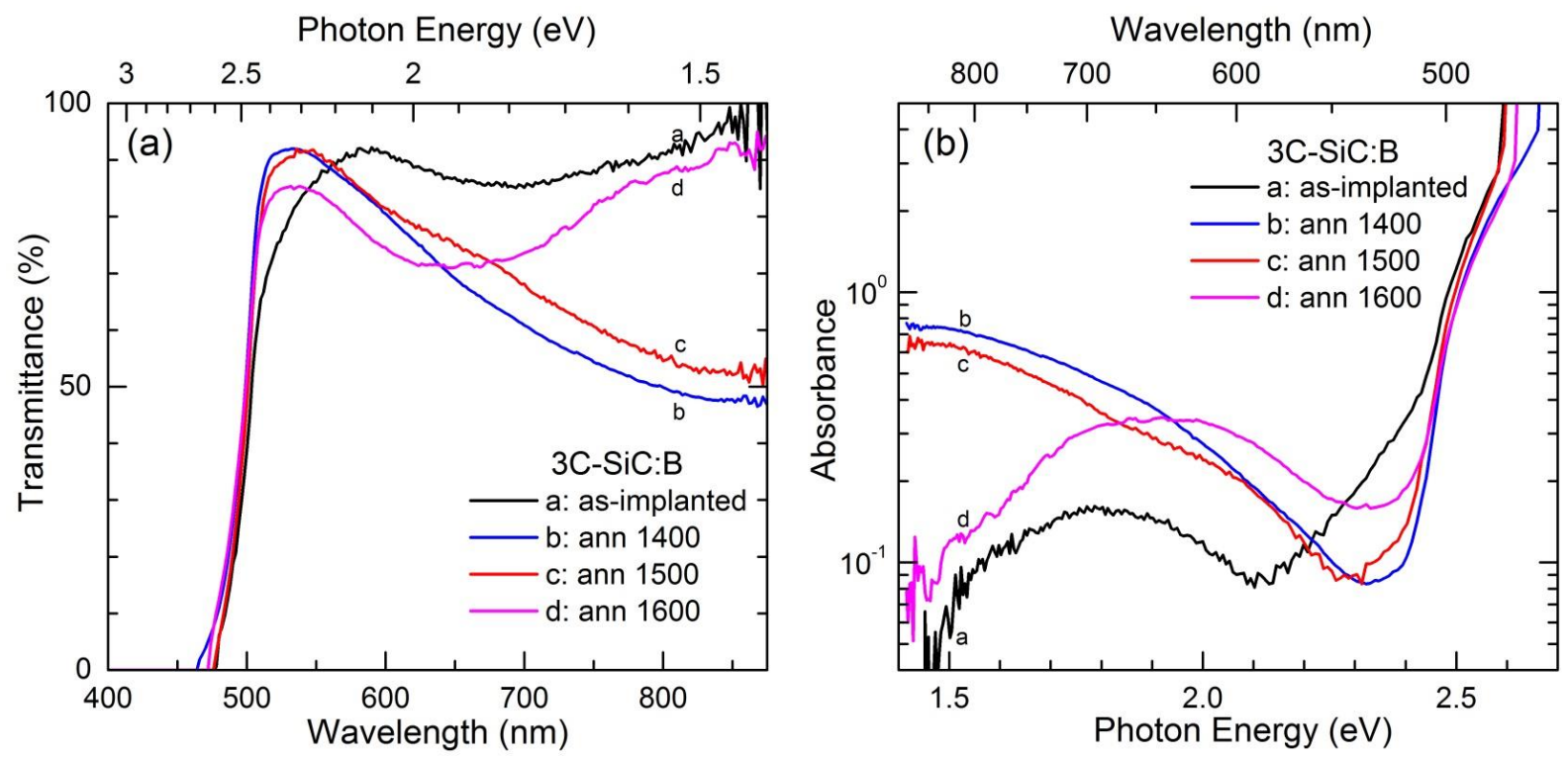

Fig.4. UV-vis transmittance (a) and absorbance (b) spectra of B-implanted 3C-SiC prior and after annealing.

depths $\geq 400 \mathrm{~nm}$, indicating that a large fraction of Si atoms remain displaced even after the annealing at 1400 and $1500^{\circ} \mathrm{C}$ but the implanted samples are still single crystalline after annealing. Apparently, the crystal quality of the B-implanted SiC layer is not significantly improved by the 1400 and even

\section{Photon Energy (eV)}

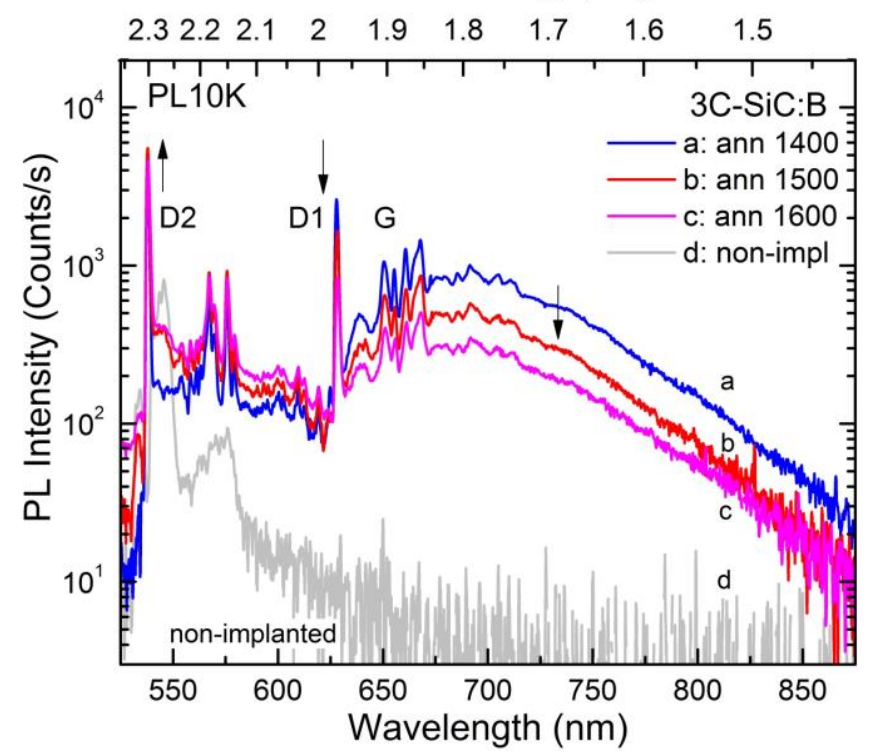

Fig.5. PL spectra obtained at 10K of B-implanted 3C-SiC after annealing at 1400,1500 and $1600{ }^{\circ} \mathrm{C}$ referenced to that of a non-implanted virgin material. $1500^{\circ} \mathrm{C}$ annealing due to the high dose implantation causing the lattice to be heavily deformed.

The optical activity of the incorporated $\mathrm{B}$ atoms was deduced from the evolution in absorption and emission spectra monitored by transmittance and PL measurements of the samples before and after post-implant annealing. Fig. 4 shows the room-temperature UV-vis transmittance and absorbance spectra of the B-implanted sample before and after annealing. The apparent build-up of a broad absorption band peaking at around $1.5 \mathrm{eV}$ is attributed to implantationinduced deep centers, presumably caused by $\mathrm{B}$ atoms replacing $\mathrm{C}$ atoms after annealing. These developments in absorbance spectra are most prominent upon post-implant annealing at $1400{ }^{\circ} \mathrm{C}$ and $1500{ }^{\circ} \mathrm{C}$ and possibly indicate formation of a boron-related IB (cf. Fig. 
1). Next, an insight into optical emission properties of the incorporated boron was attained from the low temperature PL measurements. Fig. 5 shows PL spectra obtained at $10 \mathrm{~K}$ of B-implanted 3CSiC:B after annealed at 1400,1500 and $1600{ }^{\circ} \mathrm{C}$ alongside with that of a non-implanted virgin material included for reference. Here, besides the typical high-temperature treatment evolution of the sharp spectral features (D1, D2, G lines), one can observe a newly emerging broad emission band at around $1.7 \mathrm{eV}$, which is associated with activation of deep B-centers participating in donor-to-acceptor pair and free-to-bound optical transitions. The intensity of this band decreases with increasing annealing temperature, which is similar to the trend found for the absorbance in Fig. 4(b). This clearly suggests that optimal activation temperature in pursuing boron-related $\mathrm{IB}$ in $3 \mathrm{C}-\mathrm{SiC}$ is well below $1600^{\circ} \mathrm{C}$.

\section{Conclusions}

Sublimation-grown 3C-SiC crystals were implanted with 2 atomic percent of boron ions at elevated temperature $\left(400{ }^{\circ} \mathrm{C}\right)$ using multiple energies $(100$ to $575 \mathrm{keV})$ with a total dose of $8.5 \times 10^{16}$ atoms $/ \mathrm{cm}^{2}$ to form a buried box-like concentration profile reaching $\sim 2 \times 10^{21} \mathrm{~cm}^{-3}$ in the plateau region extending from $\sim 700 \mathrm{~nm}$ to $\sim 1000 \mathrm{~nm}$ below the surface. The optical activity of the incorporated B atoms was deduced from the evolution in absorption and emission spectra indicating possible pathway for achieving an intermediate band behavior in boron doped 3C-SiC at sufficiently high dopant concentrations. These results are encouraging since they show that high quality $3 \mathrm{C}-\mathrm{SiC}$ is possible to grow, and a potential application in optoelectronics.

\section{Acknowledgments}

The authors gratefully acknowledge the financial support of this work by Norwegian Research Council (project "SunSiC" No. 461224 22971), Swedish Energy Agency, Swedish Research Council (Proj. No. 621-2014-5825) and Swedish Governmental Agency for Innovation Systems (Vinnova). The authors also acknowledge Mr. Viktor Bobal for the Boron implantation of the samples.

\section{Reference}

[1] A. Luque, A. Martí, C. Stanley, Nat. Photonics 6 (2012) 146-152.

[2] A. Luque, A. Martí, Phys. Rev. Lett. 78 (1997) 5014-5017.

[3] G. Beaucarne, A. S. Brown, M. J. Keevers, R. Corkish, M. A. Green, Prog. Photovolt: Res. Appl. 10 (2002) 345-353.

[4] M. Syväjärvi, Q. Ma, V. Jokubavicius, A. Galeckas, J. Sun, X. Liu, M. Jansson, P. Wellmann, M. Linnarsson, P. Runde, B.A Johansen, A. Thøgersen, S. Diplas, P.A. Carvalho, O. M. Løvvik, D.N. Wright, A.Y. Azarov, B.G. Svensson. Sol. Energ. Mat. Sol. C 145 (2016) 104-108.

[5] W. Suttrop, G. Pensl, P. Lanig, App. Phys. A 51 (1990) 231-237.

[6] T. Kimoto, J.A. Cooper, Fundamentals of Silicon Carbide Technology: Growth, Characterization, Devices, and Applications, Wiley-IEEE Press, 2014.

[7] S.W. Lee, S.I. Vlaskina, V.I. Vlaskin, I.V. Zaharchenko, V.A. Gubanov, G.N. Mishinova, G.S. Svechnikov, V.E. Rodionov, S.A. Podlasov, Semicond. Phys. Quantum Electron. Optoelectron. 13 (2010) 24-29.

[8] H. Kuwabara, S. Yamada, Phys. Stat. Sol. (a) 30 (1975) 739-746.

[9] P. G. Baranov, I. V. Il’in, E. N. Mokhov, Phys. Solid State 40 (1998) 31-34.

[10] V. Jokubavicius, G. Reza Yazdi, R. Liljedahl, I. G. Ivanov, R. Yakimova, M. Syväjärvi, Cryst. Growth Des. 14 (2014) 6514-6520. 